\title{
Oligopolistic competition among groups ${ }^{*}$
}

\author{
Luis C. Corchón \\ Universidad de Alicante, San Vicente del Raspeig, Alicante, Spain \\ Received 26 September 1990 \\ Accepted 31 October 1990
}

\begin{abstract}
In this paper we study an oligopolistic equilibria in which (possibly few) corporations can create as many firms as they like. It is shown by means of two examples that under constant returns to scale, Subgame Perfect Nash Equilibria implies perfect competition.
\end{abstract}

\section{Introduction}

Sometimes large corporations create several firms which compete in the same market. There are, at least, three different explanations of this policy:

(a) under decreasing returns production efficiency requires plant diversification,

(b) competition alleviates incentive problems due to moral hazard, and

(c) competing firms are a credible commitment to Stackelberg leadership of the group.

In this paper we study the impact on market equilibrium of this kind of decentralization by means of two examples, focusing our attention on point (c) above. In order to keep effects (a) and (b) away we will assume constant returns to scale and complete information. We also discuss briefly how economies of scale can affect our conclusions.

In our conditions, it may be argued that no group would wish to set up more than one plant, since what it can be achieved by means of two plants can be achieved by one with superior coordination. We will see that the above conjecture is false. In fact under linear or unit-elastic inverse demand functions perfect competition us the unique Subgame Perfect Nash Equilibrium when the number of groups is at least three. The intuitive explanation of this paradox is that by creating a new firm a group can get closer to the Stackelberg point with this group as a leader, i.e. to create an independent firm is a credible commitment. In our model each group is in a Prisioner's dilemma-like situation since by increasing the number of firms makes itself better off but if all groups follow the same policy, profits per group will fall. In other words, decentralization of decisions - which implies that control over firms within the group is lost up to some extent - enhances group performance given the behavior of competitors. However if all groups follow the same policy, under constant returns, monopoly power vanishes.

* I am grateful to C. Herrero, D. Pérez-Castrillo, A. Villar and J. Silvestre for helpful comments. This research has been partially supported by D.G.I.C.Y.T. under project PB 88-0289. 


\section{The model and the main results}

Suppose we have $k$ corporations (subsequently called groups) in a market. Each group has access to an identical technology represented by a cost function $c \cdot x_{i}$, where $x_{i}$ is the output of a firm and $c$ is the (constant) marginal cost. Each group can build as many (identical) firms as it likes. Each firm will be understood as a separate agent in the sense that it will behave independently of the rest of firms in the group. Each group will attempt to maximize the overall profit received by all the firms in the group.

There is an inverse demand function $p=p(z)$ where $z$ is total output produced by all firms of all groups, and $p$ is the price of the product. If a group, say $j$, builds $m$ firms and each of them produces an identical output $x_{j}$, profits for this group are $\pi_{\mathrm{j}}=m \cdot\left(p(z) \cdot x_{j}-c \cdot x_{j}\right)$.

The game is a two-stage game. In the first stage each group decides (independently) the number of firms in this group. In the second stage firms set (independently) the quantities to be produced. The equilibrium concept will be Subgame Perfect Nash Equilibrium (SPNE). We now study the properties of SPNE under additional assumptions on the inverse demand function.

Example 1. The inverse demand function reads $p=A / z, A>0$. If in the second stage there are in firms, profits per firm in a Cournot Equilibrium (CE) are $A / n^{2}$. Therefore if a group sets up $m$ firms its profits are $m \cdot A /(m+t)^{2}$ where $t$ is the number of firms created by its competitors (therefore $n=m+t$ ). In a SPNE each group will attempt to maximize this expression for given $t$. Forgetting the inter problem, the first-order condition is

$$
A \cdot(t-m) /(m+t)^{3}=0
$$

Since it can be proved that this condition is also sufficient we obtain that in any SPNE $m=t$. Moreover since equilibrium is symmetrical $t=(k-1) \cdot m$. Therefore if $k=2$ equilibrium is completely undetermined since any number of firms is a SPNE and if $k>2$ equilibrium implies an infinite number of firms since the best reply of any group consists of building as many firms as the total number of firms set up by its competitors. Therefore in this case perfect competition is the unique SPNE.

Example 2. Inverse demand reads $p=a-z, a>c>0$. If there are $n$ firms in the second stage, profits per firm in a CE are $(a-c)^{2} /(1+n)^{2}$. Therefore if a group sets up $m$ firms its profits are $m \cdot(a-c)^{2} /(1+m+t)^{2}$. The first-order conditions of a SPNE is

$$
(a-c)^{2} \cdot(1+t-m) /(1+t+m)^{3}=0 .
$$

Since the condition is also sufficient we get that in any SPNE $m=t+1$. Therefore if $k>1$ only perfect competition is a SPNE since the best reply of each group is to set up one more firm than their competitors.

Under economies of scale, in general, price will be greater than average cost. However we will show that if a fixed cost is considered, $m$ is strictly decreasing with $k$, i.e. a small number of groups implies ceteris paribus a greater value of $m$. Let us denote by $n^{\prime}$ the maximum number of active firms subject to non negative profits in a CE. If $p(z)$ is as in example 1 easy calculations show that $m=n^{\prime} .\left((k-2) / k^{3}\right)^{1 / 2}$ (notice that if $k=2$ there is no SPNE and that $m$ is maximum if $k=3$ ). 
Then, if $k>3, \mathrm{~d} m / \mathrm{d} k<0$. If $p(z)$ is as in example 2, $m$ is the (unique if $n^{\prime}>0$ ) solution to the equation $\left(1+n^{\prime}\right)^{2} \cdot(1+k \cdot m-2 \cdot m)=(1+k \cdot m) 3$. Implicit differentiation of this equation (when evaluated at equilibrium ) yields

$$
\begin{aligned}
\mathrm{d} m / \mathrm{d} k= & m \cdot(1+k \cdot m-3 \cdot m) / \\
& \left(2 \cdot m \cdot k-k-k^{2} \cdot m-1\right)<0 \quad \text { if } \quad k \geq 3 .
\end{aligned}
$$

\section{Conclusions}

In this paper we have shown by means of two examples that under constant returns, strategic competition among a (possibly small) number of groups may yield perfect competition. Therefore in this case the existence of few groups does not necessarily imply that they are obtaining oligopolistic rents. Under economies of scale, profits will be positive but the smaller $k$, the greater $m$, i.e. if $k$ is small, is very likely that more than one firm per group will be set. Of course, asymmetrical groups, moral hazard, heterogeneous products, and more general forms of demand and cost functions must be considered before a general conclusion is reached. What we have done in this letter is to isolate the effect of commitment via creation of firms in two special cases.

Our results may be compared with those obtained by Salant, Switzer and Reynolds (1983) in the (polar) case of merger. They find that in the linear case merger may well be unprofitable. The difference with the findings of our paper is that in our case to create a new firm is always profitable. Therefore our results are not a counterpart of theirs. Moreover it is not clear that merger can be treated as non-cooperative game. See Perry and Porter (1985) and Davidson and Deneckere (1986) for further analysis of mergers. Finally we remark that other approaches to the delegation problem [see Vickers 1985), Sklivas (1987) and Fershtman and Judd (1987)] obtain that, under linearity of the relevant functions and quantity competition, firms produce greater output under delegation than in a one-shot game. However in their case equilibrium is never perfectly competitive. This difference is explained by the fact that in their approach the first stage consists of choosing the reaction function of the firm and not, the number of firms in the group. An interesting extension of our work may be a combination of the two kinds of delegation.

\section{References}

Davidson, C. and R. Deneckere, 1986, Long-run competition in capacity, short-run competition in price and the Cournot model, The Rand Journal of Economics 17, 404-415.

Fershtman, C. and K.L. Judd, 1987, Equilibrium incentives in oligopoly, American Economic Review, $922-940$.

Perry, M. and R. Porter, 1985, Oligopoly and the incentive for horizontal merger, American Economic Review 75, $219-227$. Salant, S., S. Switzer and R. Reynolds, 1983, Losses from horizontal merger, Quarterly Journal of Economics, $185-199$. Sklivas, S., 1987, The strategic choice of managerial incentives, Rand Journal of Economics, 452-458. Vickers, J., 1985, Delegation and the theory of the firm, Economic Journal, Supplement 95, 138-147. 